\title{
Pedagogia dialógica para democratizar a educação superior
}

\author{
Ivar César Oliveira de Vasconcelos ${ }^{a}$ \\ Candido Alberto Gomes ${ }^{b}$
}

\section{Resumo}

A expansão da educação superior, abrangendo estudantes mais diversos do ponto de vista sociocultural implica necessariamente a sua democratização? Esta pesquisa questiona a aparente neutralidade das instituições educacionais, indagando se esta reproduz as relações sociais e o poder dominante. Para isso, investigou-se a interação entre as experiências sociais de jovens estudantes e de professores universitários, buscando atualizar o conceito de pedagogia dialógica. Um estudo de casos múltiplos, envolvendo duas licenciaturas, evidenciou, dentre outros, a valorização da amizade, criatividade e respeito, bem como a preocupação de todos com o desinteresse de estudantes pelo curso. Elaborou-se uma hipótese, com três eixos fundamentais das interações sociais de estudantes e professores: as tendências de culpar o outro pelo insucesso educacional e de cultivar relações autoritárias, bem como a negação da capacidade crítica dos indivíduos.

Palavras-chave: Educação superior. Democratização. Inclusão social. Pedagogia dialógica.

\section{Introdução}

Em vias de democratização, a educação superior utiliza, dentre outras bandeiras, a da inclusão social - considerada como a possibilidade de os alunos participarem da vida cidadã, ter autonomia e consciência crítica, entre outras dimensões da vida social. Neste sentido, a ação educativa estaria voltada para a emancipação social dos alunos e não para a alienação. Além de informar, a educação superior estaria formando os alunos. Porém, a intenção se cumpre na prática?

Pode ser, por exemplo, que a dita democratização, traduzida meramente em expansão da educação superior, seja a faceta de uma dinâmica a espelhar o modo

\footnotetext{
a Universidade Paulista - UNIP. Brasília, Distrito Federal, Brasil.

b Universidade Católica de Brasília - UCB. Brasília, Distrito Federal, Brasil. 
como o capitalismo contemporâneo se alarga no âmbito da educação superior. Tal alargamento teria o significado de avanço do domínio do capitalismo sobre os campos da reprodução política e social, sendo tal avanço denominado "mercado da educação", no contexto em que grupos de investimentos vinculados à rede bancária fazem aquisições de instituições de ensino. A propósito, já é conhecido que riqueza e prosperidade não garantem a justiça e o bem-estar - é bastante constatar, segundo o Fundo das Nações Unidas para a Infância (UNICEF), que duas das mais ricas economias do mundo, Reino Unido e Estados Unidos, situaram-se entre os mais baixos níveis da hierarquia de bem-estar de crianças entre 21 países industrializados cobertos por pesquisa realizada já neste século (UNICEF, 2007).

Por isto mesmo, alguns autores propõem que o atual processo de expansão da educação superior seja montado em outras bases, nas quais a formação e o conhecimento possam ser socialmente úteis (MANCEBO; VALE; MARTINS, 2015).

De fato, a que serviria tal expansão? Transforma ou reproduz as condições sociais? De acordo com a Organização das Nações Unidas para a Educação, a Ciência e a Cultura (UNESCO), multiplicou-se o número de estudantes na educação superior no mundo. Ao final do século passado, estimou-se que, em 2025, haveria 100 milhões de estudantes (JOSPIN, 1999). Em 2004, já havia 132 milhões. Considerando as taxas de crescimento adotadas pela UNESCO e a Organização para Cooperação e Desenvolvimento Econômico (OCDE), pode-se estimar mais de 170 milhões de estudantes matriculados na educação superior (UNESCO, 1999; OECD, 2010). Só no Brasil, segundo o Censo da Educação Superior de 2012, o número de matrículas superou a marca de sete milhões, registrando a média anual de crescimento da ordem de 5,7\% desde 2009 (BRASIL, 2014). Tal expansão, acompanhada pela horizontalização das oportunidades escolares, constituiria a resposta das promessas modernas de liberdade, igualdade e solidariedade - expectativas frustradas, mas ainda vivas para populações do mundo inteiro (SANTOS, 2007). Coerentemente, a UNESCO propôs para a educação no século XXI os quatro conhecidos pilares, que enfatizam o aprender a aprender, os valores e a formação de atitudes (DELORS et al., 1998).

No entanto, parece esquecido que, se as instituições de educação superior passam por importantes processos de desinstitucionalização (TOURAINE, 1997; DUBET, 1998; SANTOS, 2005), não resistir ao encaixotamento das idealizações modernas, isto é, à planificação (WILBER, 2006), significa aumentar o fosso já existente entre a origem social dos estudantes e os desafios da instituição educativa. Como tal, significa ter uma educação superior democrática, no entanto, favorável à reprodução das condições sociais e não à transformação, pois, no limite, esta educação alheia-se em relação às experiências sociais de alunos e professores, 
construídas com lógicas de ação pré-configuradas, distintas, utilizadas por uns e outros de acordo com suas capacidades de compreender o mundo, com seus anseios e sonhos (DUBET, 1994, 2013).

Certamente, ao contribuir para emancipar seus estudantes - predominantemente jovens, com rostos geracionais do século XXI (por exemplo, DICK, 2003; SAVAGE, 2009) - uma instituição de educação superior se obriga a transmitir conhecimentos, uma tendência identificada em meio aos desafios da expansão educacional. Contudo, a mera transmissão de informações e conhecimentos se torna insuficiente para o desenvolvimento de potencialidades humanas, pressuposto para incluir socialmente, isto é, emancipar. Só a transmissão de conhecimentos não atualiza a gênese humana, multidimensional, exigente para além do simples aprendizado de conhecimentos acadêmicos e familiares.

Ora, o termo "incluir" carrega em sua originalidade as ideias de implicação, envolvimento, pertencimento e inserção, portanto, considera a relação entre partes que se influenciam mutuamente (INCLUIR, 2007). Em se tratando de seres humanos, influenciar mutuamente pressupõe a construção de diálogos. Isto é, toma como base a interação social - esta tomada na qualidade de uma sequência de diálogos presentes nos encontros face a face, por meio dos quais os indivíduos marcam posições, embora também ocorra na falta de diálogo, tendo como referência a situação projetada diante uns dos outros.

Neste sentido, o processo educacional que tão somente informa, sem formar, isto é, sendo monológico, não transforma. Pelo contrário, reproduz. Preserva em seu interior características favoráveis à exclusão social, pois não observa se está desvinculando a origem social dos estudantes em relação às variações sofridas ao longo dos percursos escolares (DUBET, 2003, 2008). Tal processo desconsidera que, na sociedade atual, os indivíduos são cada vez mais responsáveis por encontrar sentido em suas ações; são responsáveis pela construção de suas "experiências sociais" (DUBET, 1994), valendo-se de lógicas de ação cuja origem está no social e não exclusivamente no nível individual. O processo que não articula informação e formação se caracteriza por promover escassa dialogicidade, desde o nível macro, envolvendo políticas públicas ou o corpo escolar, ao micro, envolvendo a prática didático-pedagógica. Efetivamente, impõe determinados padrões culturais, não respeitando a diversidade sociocultural cada vez mais ampla dos estudantes. Em vez de transformar condições sociais desfavoráveis, reproduz desigualdades.

Ao contrário, o processo educacional que articula informação com formação, baseado na pedagogia dialógica (FREIRE, 2011), pode contribuir para a inclusão 
social, pois, leva em conta tal diversidade, fundamentando-se na originalidade do termo "incluir". Articular informação e formação significa prover o processo educacional da ação educativa capaz de aproximar conhecimentos teórico-práticos do desenvolvimento humano; capaz de situar estudantes e professores numa perspectiva comum de comportamentos, atitudes, ideias e preocupações, potencializando a sequência de diálogos construídos na diversidade de valores, interesses e representações socioculturais.

Desse modo, delimitando-se teoricamente na confluência dos pares de conceitos "emancipação/alienação", "transformação/reprodução" e "experiência social/pedagogia dialógica", este texto reflete a respeito do processo educacional no contexto da educação superior em expansão, buscando identificar aspectos que articulam as dimensões informativa e formativa da educação. Tal articulação favorece a formação integral do aluno e, assim, a sua inclusão social. Neste sentido, tomando a universidade em seu desafio quanto à massificação, em paralelo à busca da efetiva inclusão dos seus estudantes, indaga-se: se o ato de incluir socialmente pressupõe estabelecer a interação social entre seres humanos e se o processo educacional inclusivo se desenvolve com base na pedagogia dialógica, só a transmissão de conhecimentos não se constituiria num efetivo filtro social?

Esta reflexão parece relevante, se consideradas as recomendações das duas conferências mundiais sobre a educação superior, realizadas pela UNESCO em 1998 e 2009. O relatório final da primeira delas recomenda que a universidade proceda "à mais radical mudança e renovação que porventura lhe tenha sido exigido empreender" (UNESCO, 1999, p. 18), considerando que a sociedade vive uma profunda crise de valores, a qual é vivida também pela universidade - senão continuará predominando o econômico, perdendo-se o que há de fundamental no âmbito da moral e da espiritualidade. Por sua vez, o relatório final da segunda conferência registra que "nunca na história foi tão importante investir na educação superior como força maior na construção de uma sociedade inclusiva e de conhecimento diversificado" (UNESCO, 2009, p. 2).

A ideia central defendida por este texto, portanto, sustentada pelos resultados de uma pesquisa empírica, é: "a educação que só informa, reproduz; a que articula aspectos informativos e formativos da educação, transforma".

\section{Democratização da educação superior ou eliminação diferida dos alunos?}

Como antes, continua a discussão a respeito de uma educação que contribui para emancipar ou alienar. Como antes, a herança vinculada à origem social dos 
estudantes explica as variações nos percursos escolares e as diferenças de capital cultural, apesar das críticas às teorias da reprodução, que não dariam conta de explicar questões como: por que, de um lado, "herdeiros" fracassam e, de outro, por que "não herdeiros" são bem-sucedidos? A favor dessas teorias, no primeiro caso, fica esquecido que os herdeiros podem optar (e não raro optam) por não serem bem-sucedidos (termo discutível), pois, valeria a pena morrer de estudar se não se cumprem as promessas de que, estudando, eles seriam no mínimo o que foram seus pais? No segundo caso, diante das conquistas dos pais, os não herdeiros podem enxergar possibilidades de sucesso educacional e profissional (e avançam...).

Com efeito, argumenta Mauger (2012), estas e muitas outras críticas não invalidariam em absoluto o modelo de reprodução, ou seja, continuariam válidas as explicações do chamado "reprodutivismo" (VIEIRA, 1996). Neste sentido, a democratização do sistema educacional se constitui em prova para as teorias da reprodução (MAUGER, 2012). O autor lembra que o contexto da explosão escolar, caracterizado pela inserção de crianças e adolescentes de classes populares até então excluídas, levou a consequências como a diferenciação crescente dos estabelecimentos escolares, apesar da unificação formal e da inflação dos diplomas. Contudo, apesar dos desafios para explicar estes novos contextos, continua basicamente válido o modelo de reprodução.

No caso da educação superior, a democratização pode ser interpretada como expansão progressiva do ensino e/ou como horizontalização das oportunidades educacionais, traduzindo apenas alguns dos inúmeros aspectos que poderiam definir o que seria uma educação para todos. Desde "Os Herdeiros" (BOURDIEU; PASSERON, 1964), por exemplo, tal ideia implicaria uma educação neutra, passível de aplicação a todos indistintamente, o que pressupunha a desvinculação entre a origem social dos estudantes e os impactos das trajetórias educacionais.

Ora, diante da expansão da educação superior em escala mundial, as instituições a ela vinculadas passaram a acolher e continuam acolhendo populações de diversificadas origens socioculturais, com impacto, por exemplo, em políticas educacionais, currículos e práticas didático-pedagógicas, embora tenha permanecido a ideia de neutralidade da escola fundamentada no ideal modernista que tudo planifica (WILBER, 2006). Não estaria a instituição educacional, por trás de sua aparente neutralidade, reproduzindo as relações sociais e o poder dominante? Não estaria substituindo as desigualdades de acesso pelas desigualdades de currículos? Parece configurar a seguinte situação: menos cumprindo a promessa de emancipação e mais alienando, a escola transmite o capital econômico e cultural como originário do mérito. 
Sabendo que uma escola brota do encontro entre educadores e educandos, ou seja, na troca de experiências em diferentes áreas, como a cognitiva, a afetivo-emocional, a motora, a social e a profissional (MASETTO, 1997), numa instituição de educação superior e, em especial, numa universidade, esta troca de experiências envolve o mundo inteiro, refletido no cotidiano construído por professores e alunos, na colaboração de funcionários, na ação contextualizada com o meio onde se insere (BUARQUE, 1994). Portanto, atualizando-se com o mundo, a escola, em quaisquer dos níveis de ensino, sofre transformações nos modelos educativos.

Neste sentido, Dubet $(1994,1998,2013)$ explica que tem ocorrido uma transformação da relativa homogeneidade desses modelos e das finalidades da instituição educativa. Conforme o autor, tal transformação estaria ocorrendo devido: 1) à massificação da escola; 2) à mudança no valor relativo dos diplomas em face do aumento de sua distribuição; 3 ) ao processo de fragmentação das fronteiras entre educação e instrução.

Para Dubet (1994), nos primeiros ciclos da universidade ficam evidenciados com maior clareza os problemas relacionados à heterogeneidade dos públicos, à estranheza dos alunos, às normas da instituição, ao desconforto dos professores frente ao nível, à angústia dos alunos. De acordo com o autor, não só no collège e no último ano do lycée (correspondem, respectivamente, aos anos finais do ensino fundamental e ao ensino médio no Brasil), mas na universidade, a escola não mais se definiria em termos de valores ou funções envolvidas, mas pela capacidade de produzir ações combinadas, configurando o fim do modelo de organização tomada como instrumento para institucionalizar valores.

No entanto, caso permaneça como instituição racionalizadora da modernidade, a universidade pode viver contradições. É o caso quando recebe um aluno que, embora tendo dominado os currículos enquanto cursa a educação básica e tendo vencido as dificuldades para acessar a educação superior (SPOSITO, 2009), a universidade lhe dedica um olhar distante da lição freireana do respeito à autonomia do ser do educando (FREIRE, 2009) - a exemplo do que identificou Roggero (2006) em suas pesquisas com relação a docentes na universidade (para alguns docentes, os alunos seriam mimados e imaturos).

Vivenciando esta contradição, a universidade se arrisca a selecionar o "tipo" de cultura a ser internalizada pelo aluno, priorizando padrões culturais médios (SANTOS, 2005) com foco na formação para o trabalho e, por consequência, priorizando o credenciamento de competências. Ao selecionar, impõe um 
arbitrário cultural (BOURDIEU; PASSERON, 1964), estabelecendo, por meio da ação pedagógica, como violência simbólica, concepções culturais de grupos e classes dominantes - aqui a universidade exclui; aqui a democratização promove a eliminação diferida dos alunos.

Assim, enquanto prova para as teorias da reprodução (MAUGER, 2012), a democratização da educação superior (ou eliminação diferida dos alunos?) pode desdobrar-se ao nível dos processos educacionais... O que incluiria socialmente? O que contribui para efetivamente emancipar? Só transmitir ou dialogar?

\subsection{Só transmitir, transmitir...}

O processo educacional que enfatiza a informação, sem que esta se articule com a formação, ou seja, mais monológico e menos dialógico, constitui a base da imposição de culturas, o que resulta em reprodução e não em transformação social. Noutros termos, o processo educacional que se volta só para a transmissão de conhecimentos, na educação superior em vias de democratização, reproduz situações de desigualdade, sem contribuir para transformar socialmente, pois se reduz a aspectos cognitivos, racionais, objetivos, relegando a segundo plano as questões emocionais, subjetivas, presentes no dia a dia das experiências sociais (DUBET, 1994, 1998, 2013) de alunos e professores. Reproduz porque "iguala" os desiguais. Cabe esclarecer que o conceito "experiências sociais" implica as condutas coletivas e individuais perpassadas pela heterogeneidade de seus princípios constitutivos e pela ação de cada indivíduo, responsável este por construir o sentido de suas práticas no interior desta heterogeneidade (DUBET, 1994). É justamente nesta heterogeneidade de princípios e ações que a imensa quantidade de informações circula pelo mundo, pressionando os indivíduos, causando dispersão e confusão, com frequência gerando o que Tavares (1996) denomina iletrados diplomados.

Como sublinha Alarcão (2008), vive-se numa sociedade complexa, marcada por uma enorme riqueza informativa em que as pessoas têm dificuldades para lidar com informações novas, que as inundam e se entrecruzam com ideias e problemas, oportunidades, desafios e ameaças. É o mundo da informação fragmentária, acumulada. Uma sociedade que tem o pendor para o saber desorganizado e problemático. No entanto, apesar de tal riqueza informativa, o risco de se estabelecer um processo educacional baseado no acúmulo de conhecimentos existe, em detrimento de uma melhor formação pessoal e social. Se tal ocorre, nos termos de Freire (2011), o professor entende ter o papel de "encher" os alunos de conhecimentos com o objetivo de transformá-los em depósitos de conteúdos, como se estes fossem o verdadeiro saber. Seria, conforme o autor, uma "educação 
bancária", a qual Sartre (1960) poderia perfeitamente chamar de concepção "digestiva" ou "alimentícia do saber", em que este assume a conotação de uma iguaria, um tratamento de engorda.

No caso da universidade, a pura transmissão de conhecimentos pode encontrar terreno fértil na enorme expansão da educação superior. A universidade passou a receber populações de alunos de diversas formações socioculturais, em sua maioria sendo hábeis na arte de dominar tanto o currículo da sala de aula como também o currículo da rua, socializando-se de qualquer modo, embora exercendo protagonismos (GOMES; VASCONCELOS; LIMA, 2012). Um cenário que desafia a universidade, colocando-a na linha do risco que bate às portas da pedagogia antidialógica, conteudista e monológica (FREIRE, 2011), envolvida com uma racionalidade coerente com a modernidade sólida (BAUMAN, 2001).

A pura transmissão de conhecimentos emerge também quando a universidade recorre à ideologia da relação "causa-efeito": por exemplo, a ideia de profissionalizar para ter emprego - facilmente identificada nos tempos atuais! Neste caso, prioriza-se o desenvolvimento de competências para o mundo do trabalho. Os estudos de Pais (2003) acerca das relações entre educação e trabalho, no âmbito da educação superior, demonstraram experiências sociais de jovens universitários portugueses envoltos pela ideia da profissionalização como solução do desemprego. Para o autor, embora a massificação do ensino e a generalização dos estudos universitários desenvolvam altas expectativas de mobilidade social entre os jovens, estes têm se frustrado por não poderem desfrutar de status sociolaboral correspondente aos títulos acadêmicos obtidos.

Povoam prioritariamente este cenário dois atores. No caso da educação brasileira, de um lado, está o universitário, representado por uma jovem aluna de instituição privada, que ingressa na educação superior com 18 anos de idade, no curso presencial noturno, tendo optado pelo bacharelado (BRASIL, 2014). Este universitário, às vezes, tem sido percebido por alguns professores como um indivíduo mimado, indisciplinado, preguiçoso, imaturo, falante, dependente, com deficiência de leitura e escrita, com valores frágeis, que pouco estuda e não se esforça (ROGGERO, 2006). De outro lado, está o professor universitário, representado por alguém do sexo masculino, com 35 anos de idade, tendo o grau de doutor e trabalhando em tempo integral, caso atue numa instituição pública; tendo o grau de mestre e sendo horista, caso atue em instituição privada (BRASIL, 2014).

São eles, aluno e professor, participantes de uma peça teatral que se desenrola no palco da chamada democratização da educação superior. No entanto, para serem 
efetivamente protagonistas, precisam que essa democratização não se reduza à transmissão de conhecimentos, mas se desenvolva mais para lá... no lugar onde se encontra o diálogo.

\subsection{Dialogar para incluir}

O processo educacional que assume uma pedagogia dialógica, isto é, que articula aspectos informativos e formativos da educação, contribui para incluir socialmente. Compreende-se a articulação informar-formar como a ação educativa capaz de aproximar conhecimentos teórico-práticos e desenvolvimento humano, portanto, sem restringir a formação à construção de conhecimentos, tendo como pano de fundo a integração entre saber e consciência, a ser realizada por meio do uso de princípios que organizam os saberes, de modo a evidenciar sentidos e gerar competências para propor e tratar problemas. Com efeito, como ensina Freire (2011), antes de ser pura transmissão de conteúdos, a educação problematizadora do mundo é dialógica, considerando a relação Eu-Tu (BUBER, 2009) nessa problematização. Caso esta educação seja internalizada pelas diversas instâncias da universidade - um "multiálogo", nos termos de Mehta (2012) -, o processo educacional desenvolvido na sala de aula pode assumir novo significado, no equilíbrio entre o conhecimento teórico, indagador, e o desenvolvimento humano. Neste caso, atua o professor de modo a contribuir para que os alunos, neste diálogo com o mundo, sejam capazes de se problematizarem, de descobrir ou divisar o "inédito viável", transcendendo situações-limites; os contextos pedagógicos se ampliam da sala de aula para os diversos cenários de encontro entre educandos e educadores - a educação sendo ato cognoscente, e não um depósito de conhecimentos e valores. Tal processo educacional, baseado na pedagogia dialógica, articula a dimensão informativa à formativa da educação, integrando saber e consciência.

$\mathrm{O}$ que se encontra em jogo, neste entrelaçamento entre aspectos informativos e formativos da educação, é a reforma do pensamento proposta por Morin (2008). Com ela, os indivíduos conseguem superar o atual dilema entre sofrer o bombardeio de informações sobre si ou reter dessas informações só o que para eles é inteligível. Em vez do acúmulo de saberes, está a simultânea disponibilização de aptidões para colocar e tratar problemas, bem como a disponibilização de princípios organizadores que possibilitam conectar os saberes, dando-lhes sentido (MORIN, 2008). Tal entrelaçamento se torna chave da educação que contribui para formar integralmente os indivíduos; para desenvolver a capacidade de pensar e aprender de modo estratégico, relacionando-se, intervindo e sobrevivendo no mundo atual, em constante mudança (TAVARES, 1996). Portanto, refere-se aqui a um entrelaçamento 
que está na raiz da educação desenvolvida na esteira de experiências coletivas e polissêmicas tomadas como relevantes na formação integral do indivíduo. Uma educação que considera o indivíduo um ser que pensa, se emociona e age, sendo capaz de construir significados na relação aberta com os semelhantes. Que, como lembra Morin (2008), não forma para uma "cabeça bem cheia", mas para uma "cabeça bem-feita". Que concretiza as potencialidades humanas e, por isto, inclui socialmente o indivíduo, na busca de soluções para os problemas do mundo. Enfim, tal educação - desenvolvida na confluência entre informar e formar - considera a relevância de estabelecer maior abertura dos sentimentos, sem a qual o ser humano não desenvolve a melhor compreensão dos limites de suas ações e palavras nem aperfeiçoa habilidades para realizar intercâmbios e concretizar projetos coletivos e solidários (MORAIS, 2008).

Para visualizar melhor a prática didático-pedagógica assim perspectivada, recorre-se à divisão tripartida dos conteúdos, presente nos Diseños Curriculares Base (BOLÍVAR, 2000; COLL, 2001) e nos Parâmetros Curriculares Nacionais (BRASIL, 1997): conceituais, procedimentais e atitudinais. Se a escola tem a função de estabelecer o projeto educativo voltado para o desenvolvimento de conhecimentos, habilidades e atitudes, utilizando espaços e condições apropriados a partir de metodologias específicas, será a sala de aula o lugar prioritário no cumprimento dessa função, por meio da vivência de situações novas e de ruptura com valores e conhecimentos em obsolescência. Neste caso, a revisão do programa, efetuada com os alunos, promoveria o dinamismo necessário capaz de ressaltar os objetivos educacionais informativos e formativos (MASETTO, 1997).

O que significa, portanto, que, para lá da simples transmissão de conhecimentos, a educação que busca incluir socialmente o indivíduo conta com o projeto educativo que olha para o aluno em sua capacidade de pensar, sentir e agir e, por isto, articula entre si os conteúdos conceituais, procedimentais e atitudinais. Assim, tal projeto contribui para a formação integral do indivíduo ao articular os conhecimentos teóricos com o desenvolvimento humano, o saber com a consciência, estabelecendo ligações profundas entre "conhecer", "fazer" e "querer-conhecer-fazer". Com os conteúdos conceituais, constrói-se o potencial intelectivo para operacionalizar símbolos, ideias, imagens e representações, numa dinâmica de aprendizagem que envolve a memorização de fatos e a organização da realidade (é o saber). Com os procedimentais, $\mathrm{o}$ aluno aprende a decidir e a realizar ações sequenciadas, ordenadas, visando a atingir metas (é o saber-fazer). Com os conteúdos atitudinais, na totalidade dos conhecimentos e nas interações sociais (sequência de diálogos) desenvolvidas na escola, geram-se atitudes relativas ao conhecimento, ao professor, 
aos colegas, às disciplinas, às tarefas e à sociedade (é o querer-conhecer-fazer) (COLL et al., 1998; VASCONCELOS, 2012).

Desse modo, ao articular estes tipos de conteúdos, o projeto educativo concretiza o diálogo currículo-aluno, favorecendo a coautoria e o protagonismo da aprendizagem (GOMES, 2011), bem como a construção de sentido por parte do aluno. Nessa articulação, interconectam-se a concepção de ser humano e o projeto educativo, conforme apresenta o Quadro 1.

Tais interconexões pressupõem as interações sociais face a face, desenvolvidas na sala de aula (THOMPSON, 1998), compatibilizando com a educação que inclui socialmente, pois, ao pressupor o diálogo, consideram as experiências sociais (DUBET, 1994) de alunos e de professores construídas dentro e fora da escola - efetivamente, articulam processos de aprendizagem vivenciados na sala de aula com as condições sociais dos indivíduos (GOFFMAN, 1985).

Assim, a pesquisa a seguir apresentada busca verificar a ideia central defendida neste artigo, que é: a educação que só informa, reproduz; a que articula aspectos informativos e formativos da educação, transforma. Apresentará aspectos da pedagogia antidialógica, favoráveis para reproduzir desigualdades, bem como da pedagogia dialógica, favoráveis para promover a transformação social.

Quadro 1. Interconexões entre concepção de ser humano e projeto educativo.

\begin{tabular}{|c|c|c|c|}
\hline \multicolumn{2}{|c|}{ Ser humano } & \multicolumn{2}{|c|}{ Projeto educativo } \\
\hline Quem é: & Como se manifesta: & Que é: & Como se manifesta: \\
\hline $\begin{array}{l}\text { Por sua natureza } \\
\text { biológica, o ser } \\
\text { humano tem } \\
\text { capacidade para: }\end{array}$ & $\begin{array}{l}\text { Dentre outros } \\
\text { aspectos, o ser } \\
\text { humano evidencia } \\
\text { sua existência ao: }\end{array}$ & \begin{tabular}{|c|} 
O projeto educativo \\
que contribui para o \\
desenvolvimento integral \\
do ser humano promove a \\
articulação entre informação \\
e formação. Portanto:
\end{tabular} & $\begin{array}{l}\text { Este projeto educativo } \\
\text { fica evidenciado no } \\
\text { processo educacional } \\
\text { que articula os } \\
\text { diversos conteúdos, } \\
\text { tais como: }\end{array}$ \\
\hline \multirow{3}{*}{$\begin{array}{c}\text { Raciocinar } \\
\text { Agir } \\
\text { Emocionar-se }\end{array}$} & Conhecer & \begin{tabular}{|c|} 
Respeita os diversos saberes \\
adquiridos por alunos e \\
professores \\
(SANTOS, 2007)
\end{tabular} & $\begin{array}{l}\text { Conceituais } \\
\text { (o saber) }\end{array}$ \\
\hline & Fazer & \begin{tabular}{|l|} 
Volta-se para a construção \\
de valores (BOLÍVAR, 2000).
\end{tabular} & $\begin{array}{l}\text { Procedimentais } \\
\text { (como fazer) }\end{array}$ \\
\hline & $\begin{array}{l}\text { Querer conhecer } \\
\text { e fazer }\end{array}$ & $\begin{array}{l}\text { Mantém equilíbrio entre } \\
\text { razão e emoção } \\
\text { (CASASSUS, 2009). }\end{array}$ & $\begin{array}{c}\text { Atitudinais } \\
\text { (querer-conhecer-fazer) }\end{array}$ \\
\hline
\end{tabular}

Fonte: Elaboração dos autores, com base em Vasconcelos (2012). 


\section{Metodologia}

A pesquisa se caracteriza como qualitativo-exploratória, delineada como estudo de caso. Escolheu-se esta opção porque as questões de pesquisa enfatizaram o "como" e o "porquê", portanto, referiram-se mais a vínculos operacionais do que a frequências (YIN, 2010). Além disso, os dados foram fornecidos mais por pessoas e menos por papéis, em eventos contemporâneos reais, sobre os quais os pesquisadores tiveram pouco controle (GIL, 2002; STAKE, 1995). E, como as oportunidades de análise tiveram que ser replicadas, justificou-se a utilização do estudo de casos múltiplos (YIN, 2010). A pesquisa foi realizada numa universidade privada de Brasília, envolvendo cursos de licenciatura em Letras e em Pedagogia, tendo contado com a participação de oito jovens estudantes e seis professoras, conforme se apresenta no Quadro 2.

Optou-se por uma universidade porque, dentre outros aspectos: 1) propõe-se a educar a educação básica ao formar profissionais que nesta atuarão; 2) constitui componente essencial num sistema contínuo com início na educação infantil e ensino fundamental; 3) obriga-se constitucionalmente a associar ensino, pesquisa e extensão; 4) as universidades brasileiras concentraram, em 2012, 54,2\% das matrículas em cursos de graduação, apesar de representarem apenas $8,0 \%$ do total de instituições da educação superior (BRASIL, 2014).

Optou-se por um curso de Letras porque, dentre outros aspectos, propõe-se a: 1) evidenciar a relação dialética entre o pragmatismo da sociedade e o cultivo de valores humanistas; 2) promover associação entre ensino, pesquisa e extensão com base na ideia de currículo como construção cultural capaz de propiciar aquisição do saber de modo articulado (BRASIL, 2001). Optou-se por um curso de Pedagogia porque, dentre outros: 1) caracteriza-se

Quadro 2. Campo de pesquisa e participantes.

\begin{tabular}{|c|c|c|c|}
\hline \multicolumn{2}{|c|}{ Campo da pesquisa } & \multicolumn{2}{c|}{ Participantes } \\
\hline \multirow{2}{*}{ Universidade } & Cursos & \multicolumn{2}{c|}{ Casos únicos } \\
\cline { 3 - 4 } Privada & $\begin{array}{c}\text { Licenciatura } \\
\text { em Letras }\end{array}$ & 1 & $\begin{array}{c}\text { Interações sociais entre quatro estudantes do } \\
\text { curso de Letras e três professoras deste curso. }\end{array}$ \\
\cline { 2 - 4 } & $\begin{array}{c}\text { Licenciatura } \\
\text { em Pedagogia }\end{array}$ & 2 & $\begin{array}{c}\text { Interações sociais entre quatro estudantes do } \\
\text { curso de Pedagogia e três professoras deste curso. }\end{array}$ \\
\hline $\mathbf{1}$ & $\mathbf{2}$ & $\mathbf{2}$ & $\mathbf{1 4}$ participantes \\
\hline
\end{tabular}

Fonte: Elaboração dos autores (2014). 
como multimodal, tendo cinco modalidades formativas (BRASIL, 2006); 2) compromete-se com estudantes e professores em concretizar o processo educacional que prioriza a pesquisa com foco na construção de amplo diálogo na universidade. Oportuno é informar que, entre 2007 e 2009, esses cursos tiveram, respectivamente, $79,0 \%$ e $74,0 \%$ de estudantes trabalhadores (RISTOFF, 2013). Assim, estes cursos se apresentaram favoráveis não só à exploração do tema de pesquisa, mas à realização de um estudo de casos, pois em jogo estavam perguntas que enfatizaram os modos e os motivos pelos quais se desenvolviam determinadas interações sociais entre estudantes jovens e professores universitários.

Os primeiros foram selecionados do total de 693 estudantes matriculados nos dois cursos pesquisados, assim compondo-se: 1) 416 do curso de Letras, com 56 matriculados nas disciplinas Prática de Análise da Linguagem III, Prática de Análise da Linguagem IV e Sintaxe e suas Interfaces; 2) 277 do curso de Pedagogia, com 96 matriculados nas disciplinas Matemática e seu Ensino e Estágio Supervisionado I/Prática no Ensino Fundamental. Já as professoras participantes foram selecionadas dentre o total de 38 professores dos dois cursos, composto por: 1) 12 professoras e seis professores do curso de Letras; 2) 11 professoras e nove professores do curso de Pedagogia. Cada disciplina mencionada contribuiu com uma professora, com exceção da última, que contribuiu com duas. Desse modo, respectivamente, estudantes e professoras foram proporcionalmente 1,15\% e $15,78 \%$ dos totais apresentados.

Lembrando que o estudo de caso não se constitui numa investigação por amostragem (STAKE, 1995; YIN, 2010), no sentido de uma miniaturização da realidade para fazer generalizações clássicas, cabe informar que foram utilizadas mais de uma fonte de evidência. Assim, para a coleta e a geração de dados valeu-se da observação, entrevista e análise documental, apresentadas no Quadro 3, justapostas às técnicas, instrumentos e procedimentos.

Como estratégia geral de análise de dados, optou-se pela alternativa denominada por Yin (2010) como "Proposições teóricas", conforme Quadro 4. Tal estratégia foi operacionalizada a partir de quatro tipos de questões desenvolvidas pela investigação: 1) questões de nível 1, de baixa abrangência, elaboradas durante o relato central de cada participante, e feitas no mesmo encontro, incluindo assuntos específicos narrados durante a entrevista. As respostas foram obtidas com a análise dos dados gerados nos relatos de vida; 2) questões de nível 2, de média abrangência, limitando-se ao corpo discente e ao corpo docente, elaboradas previamente, perpassando os instrumentos de coleta e geração de dados. As respostas foram 
Quadro 3. Fontes de evidência, técnicas, instrumentos e procedimentos.

\begin{tabular}{|c|c|c|c|}
\hline Fontes & \multicolumn{2}{|c|}{ Técnicas e instrumentos } & Procedimentos \\
\hline Observação & $\begin{array}{c}\text { Observação } \\
\text { direta }\end{array}$ & $\begin{array}{c}\text { Roteiro de } \\
\text { observação na } \\
\text { sala de aula }\end{array}$ & $\begin{array}{c}\text { Técnica utilizada em 24 aulas (quatro aulas } \\
\text { de cada professora participante) }\end{array}$ \\
\hline Entrevista & $\begin{array}{c}\text { Roteiro de } \\
\text { vidato de } \\
\text { Roteiro de } \\
\text { replicação }\end{array}$ & $\begin{array}{c}\text { Técnica utilizada 27 vezes (duas vezes } \\
\text { para sete estudantes, duas vezes às seis } \\
\text { professoras e uma vez a um dos estudantes) }\end{array}$ \\
\cline { 2 - 5 } Análise & $\begin{array}{c}\text { Entrevista } \\
\text { estruturada } \\
\text { documental }\end{array}$ & $\begin{array}{c}\text { Roteiro da } \\
\text { validação de } \\
\text { resultados }\end{array}$ & $\begin{array}{c}\text { Técnica utilizada duas vezes, com dois } \\
\text { grupos de participantes (cada grupo } \\
\text { formado por um estudante e uma } \\
\text { professora do mesmo curso) }\end{array}$ \\
\hline e crítica & $\begin{array}{c}\text { Roteiro } \\
\text { de análise } \\
\text { documental }\end{array}$ & $\begin{array}{c}\text { Técnica utilizada oito vezes (uma vez } \\
\text { em relação ao PPC, uma vez ao PPC de } \\
\text { Pedagogia e uma vez a cada um dos seis PE } \\
\text { das disciplinas das professoras participantes) }\end{array}$ \\
\hline
\end{tabular}

PPC: Projeto Pedagógico do Curso de Letras; PE: Planos de Ensino.

Fonte: Elaboração dos autores (2014).

Quadro 4. Estratégia geral de análise, níveis das questões e técnicas.

\begin{tabular}{|c|c|c|}
\hline Estratégia geral & Níveis das questões & Técnicas \\
\hline $\begin{array}{c}\text { Proposições teóricas que } \\
\text { levaram ao estudo de } \\
\text { casos múltiplos } \\
\text { (YIN, 2010). }\end{array}$ & 1 e 2 & $\begin{array}{c}\text { Análise de conteúdo (BARDIN, 2009) } \\
\text { Valência das experiências sociais } \\
\text { (a partir de DUBET, 1994) }\end{array}$ \\
\cline { 2 - 3 } & 3 e 4 & $\begin{array}{c}\text { Síntese cruzada de casos } \\
\text { (STAKE, 1995; YIN, 2010) }\end{array}$ \\
\hline
\end{tabular}

Fonte: Elaboração dos autores (2014).

obtidas com a análise dos dados gerados pelos relatos de vida e entrevistas semiestruturadas, bem como dos dados coletados nas observações diretas e análises críticas-interpretativas; 3) questões de nível 3, de grande abrangência, alcançando o padrão das descobertas dos casos únicos, elaboradas e respondidas após as análises dos dados coletados e gerados; 4) questões de nível 4, de maior abrangência, alcançando todo o estudo.

Cabe acrescentar que as questões de níveis 1 e 2 enfatizaram o "como" e as de níveis 3 e 4 o "porquê", compatibilizando com a opção por um estudo de casos múltiplos. 


\section{Resultados e análises}

\subsection{A (des)articulação entre informar-formar: a descoberta de uma estrutura conceitual que pode explicar a reprodução social}

A pesquisa identificou consenso entre os participantes, que é a preocupação com o desinteresse de estudantes pelo curso, sendo, de certo modo, positivo na articulação entre aspectos informativos e formativos da educação. Isto porque tal consenso se fez acompanhar por um sentimento de autorresponsabilidade pela interação social, o que poderia ser utilizado como recurso para "trazer" os estudantes para o curso. No entanto, como ficou evidenciado, se este sentimento é construído pelos estudantes na crítica normativa e cognitiva aos modos de socialização, as professoras o constroem na aceitação a valores consagrados. Traduzido em outros termos, tem-se que, no mesmo plano, estudantes e professoras convergiram para a preocupação com o desinteresse de formandos em licenciaturas, apresentando alguma responsabilidade pela interação social entre todos. Em planos diferentes, todavia, divergiram, pois a autorresponsabilidade é construída com base em valores que, entre os estudantes, resultam de um processo dinâmico e, entre as professoras, resultam de um processo que parece cristalizado. Em tempo, a combinação disto tudo a favor do maior interesse de estudantes pelo curso configura um desafio para a universidade.

Esta convergência e divergências parecem se relacionar com a inércia de um sistema educativo que ora se desenvolve em meio a velhos valores, ora é operacionalizado conforme novos princípios, interesses e modos de construir identidades sociais. Na base desta inércia se descobriu que está o hábito de "culpar o Outro" por resultados indesejáveis. É a atribuição de responsabilidade de uns pelos outros (ROTTER, 1990). O Outro é o culpado preferencial pelo fracasso educacional.

Simultaneamente, a pesquisa identificou que a articulação ou a polarização entre informar e formar, respectivamente, abre perspectivas à construção de dois tipos de experiências sociais: as que contribuem para se cumprirem os quatro pilares da educação para o século XXI e aquelas que não contribuem. Estas possibilidades de operacionalizar o processo educacional apresentaram uma tensão subjacente à ação docente e à institucional: o equilíbrio entre autoridade e liberdade, o qual, frequentemente, tem sido explicado pela literatura em termos de rompimento entre autoritarismo e licença (FREIRE, 2009). Parece que, na base das mencionadas possibilidades, no momento em que geram a dita tensão, há uma espécie de autoritarismo, agora ornamentado pelas cores 
da fragmentação. No fundo, um autoritarismo que se traduz no distanciamento entre informar-formar. Descobriu-se que, em sua base, está a "primazia da informação", caracterizando o processo educacional oscilante entre contribuir ou impactar o aprendizado de novas formas de conhecer, fazer, conviver e ser (DELORS et al., 1998).

Por fim, foi evidenciado que os estudantes não conseguem expressar plenamente opiniões sobre o curso, pois receiam fazer críticas abertas aos professores e até mesmo à direção. Os professores não conseguem mudar estruturas do processo educacional. Este contexto, de meias-críticas, parece relacionar-se com um sistema que nega parcialmente o sujeito, o qual teria na base uma "crítica silenciosa". Desse modo, infere-se uma estrutura conceitual em torno de três conceitos, inércia, negação parcial do sujeito e autoritarismo, o que, presumidamente, pode explicar o quadro geral de reprodução das condições sociais dos participantes da pesquisa.

Contudo, antes de apresentar tal estrutura conceitual, bem como alguns potenciais da pedagogia dialógica identificados pela pesquisa, seguem constatações desta a respeito da ação docente e ação institucional.

\subsection{Ação docente}

O uso de uma estratégia geral de análise de dados dos casos múltiplos (YIN, 2010) possibilitou o seguinte questionamento: se há determinados potenciais no cotidiano do processo educacional estudado, como foi identificado pela pesquisa, por que algumas expectativas não se cumprem? A resposta às questões situadas no âmbito da ação docente praticada no contexto dos casos estudados, elaboradas após as análises do corpus da pesquisa, foi categórica: estes potenciais precisam ser aproveitados em favor da pedagogia dialógica ${ }^{1}$ (Quadro 5).

\subsection{Ação institucional}

O uso da estratégia geral de análise de dados dos casos múltiplos (YIN, 2010) possibilitou elaborar, além das questões apresentadas no Quadro 5, outras que se inscreveram no âmbito da ação institucional. Se aquelas questões tiveram uma só resposta a partir dos dados empíricos resultantes da pesquisa, estas agora se propuseram a abrir perspectivas para outros estudos. A Figura representa a matriz lógica de todas as questões elaboradas (de níveis 1, 2, 3 e 4).

Para elaborar as seis questões, com foco no "porquê", e obter para todas elas esta resposta, tomou-se a forma lógica: (Se p, q.); (p. à q.). Ou seja, se ocorre "p", então ocorre "q"; ocorreu "p", então ocorreu "q". Aqui "o conectivo 'se... então' coloca esses dois enunciados [...] numa relação recíproca bem definida" (SALMON, 1993, p. 13). Por " $p$ " e " $q$ " deve-se compreender enunciados (por exemplo, " $p$ " é uma representação constituída pelas variáveis "a", "b" e "c"). 
Quadro 5. Lógica e aspectos das questões elaboradas após as análises.

Potenciais e expectativas: se $\mathbf{p}$, então $q$

Há consenso em torno de uma autorresponsabilidade pela maior interação social (A) e isto é importante para haver interesse pelo curso e construir novas atitudes (B) (COLL et al., 1998). A pedagogia dialógica "vincula" consenso e sua concretização a favor do maior interesse pelo curso (C). Então, estudantes seriam interessados pelo curso. Por que não ocorre?

Há estudantes críticos (A) e isto é importante para desenvolver atividades de pesquisa (DEMO, 2007) e extensão (B). A pedagogia dialógica aciona a capacidade de crítica e, assim, favorece a associação ensino-pesquisa-extensão (C). Então, esta associação seria concretizada em larga medida. Por que não ocorre?

A pesquisa e a extensão são valorizadas pelos estudantes (gostariam de participar) (A) e isto as favorece e, por desdobramento, contribui para diversificar atividades (B) (DEMO, 2007; SÍVERES, 2010). A pedagogia dialógica aciona a valorização da pesquisa e extensão (C). Então, a partir de projetos de pesquisa/extensão, as atividades seriam diversificadas. Por que não ocorre?

Professores narram experiências pessoais e profissionais, estudantes recebem bem a iniciativa (A), sendo isto importante para articular conteúdos (B) (COLL et al., 1998). A pedagogia dialógica aproxima educador e educandos, contribuindo para articular aspectos cognitivos e socioemocionais (C). Então, o equilíbrio entre estes aspectos seria evidente. Por que não ocorre?

Estudantes desejam maior aplicabilidade de feedbacks (A) e a disposição para dar e receber feedbacks é, a priori, condição para a troca de informações entre estudantes e professores (B) (FREIRE, 2011). A pedagogia dialógica é um exercício de empatia (C). Então, deveria haver essa prática. Por que não ocorre?

Estudantes já internalizaram o "porquê" do curso (A) e isto é importante para desenvolver uma relação educativa madura (B) (FREIRE, 2009, 2011). A pedagogia dialógica aciona a capacidade de crítica e, assim, contribui para construir condutas compatíveis com a futura atuação profissional (C). Então, deveriam estar mais visíveis, entre estudantes, aspectos necessários à atuação profissional futura. Por que não ocorre?

\section{Expectativas não cumpridas e} motivos: não q; não $p$

Há estudantes desinteressados pelo curso porque, dentre outros motivos e, conforme a pesquisa (neste e nos casos a seguir), a valorização da interação social está subaproveitada (ausência da asserção C).

Há fragilidade na associação entre ensino, pesquisa e extensão porque, dentre outros, não se aproveita a criticidade dos estudantes (ausência de C).

Há um "afunilamento" das atividades para a exposição oral porque, dentre outros, não se aproveita a valorização das atividades de pesquisa e extensão (ausência de C).

Priorizam-se aspectos cognitivos, apesar das oportunidades (narrativas de experiências) de equilibrá-los com os socioemocionais, porque se canaliza a ação docente para certo "distanciamento mínimo" dos estudantes (ausência de C).

A troca de informações sobre aspectos importantes do processo educacional não é uma prática comum porque, com frequência, responsabiliza-se o "Outro" pelo insucesso escolar (ausência de C).

Estudantes percebidos como imaturos, sem se voltar para a futura profissão docente, porque sua capacidade de crítica é percebida sem muita nitidez. Não se constata que eles já possuem uma boa consciência para o curso (ausência de C).

$p$ e q: Representações de enunciados; A, B e C: Representações de enunciados que, por sua vez, compõem a premissa representada por $p$.

Fonte: Elaboração dos autores (2014). 
Na Figura, os retângulos à esquerda apresentam âmbitos das contribuições de experiências sociais resultantes da articulação informar-formar, as quais atuam sobre o cumprimento dos quatro pilares da educação para o século XXI (DELORS et al., 1998). Já os retângulos à direita apresentam âmbitos dos impactos da ausência desta articulação, os quais atuam também sobre este cumprimento no âmbito dos cursos pesquisados. Os círculos no centro contêm os pilares. As setas que chegam até estes mostram a direção das contribuições e impactos, sendo apenas um direcionamento inicial, para efeitos didáticos, pois na prática todos se vinculam entre si. $\mathrm{O}$ círculo mais abrangente, que enlaça a maior parte da figura, contém aspectos relacionados com o interesse dos estudantes pelo curso e à postura profissional que eles aprendem a assumir durante a formação. Assim, cada pilar recebe um tipo de contribuição e sofre um tipo de impacto, situando-se no contexto das

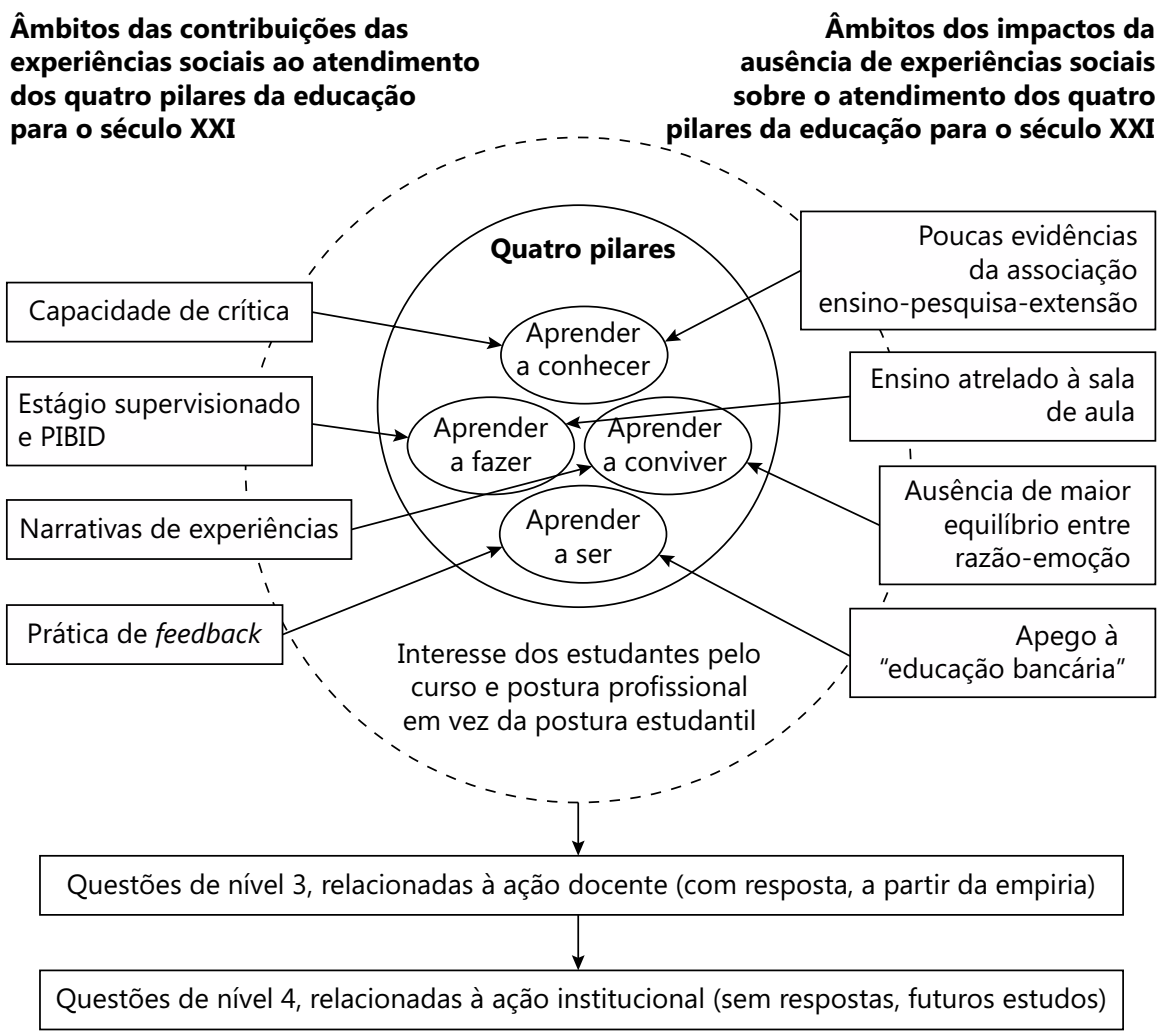

PIBID: Programa Institucional de Bolsa de Iniciação à Docência. Fonte: elaboração dos autores (2014).

Figura. Lógica das questões elaboradas. 
relações que certas lógicas de ação estabelecem entre si, portanto, envolvendo a interação entre experiências sociais.

Na parte inferior da Figura estão duas setas largas a indicar que, do entrelaçamento das contribuições e impactos, resultaram as questões de níveis 3 e 4 . Embora apareçam sequenciadas na figura, na realidade elas mantêm uma relação dialética. Isto porque as primeiras se situam no âmbito da ação docente e as segundas, no âmbito da ação institucional, implicando uma só totalidade.

Assim, as primeiras questões foram respondidas com base nos dados empíricos. As segundas, elaboradas a partir dos aspectos implícitos à resposta encontrada para aquelas, ensejam novos estudos. Eis estas questões: Em que medida ações institucionais da universidade pesquisada têm valorizado amplo diálogo entre corpo acadêmico e sociedade? Como os cursos se comprometem com um processo educacional que valoriza a pesquisa? E a extensão? Como enfrentam o desafio da perspectiva da educação bancária, unificadora e empobrecedora da realidade? Tem a ação institucional valorizado e operacionalizado efetivamente estratégias educacionais com foco na diversificação de atividades? Existem e, em caso afirmativo, quais as iniciativas institucionais que contribuem para haver uma comunicação eficaz e útil à ação docente? Existiriam iniciativas institucionais voltadas para a prática continuada de feedbacks? Quais? Em que medida tem sido feito um acompanhamento dos processos de conscientização dos estudantes sobre as diversas realidades dos cursos?

\section{Hipótese}

\subsection{As evidências da pedagogia antidialógica}

Pelo exposto até o momento, constata-se que o estudo evidenciou, por um lado, a intensidade com que determinadas estruturas sociais da universidade recaem sobre as relações sociais presentes no cotidiano de estudantes e professores e, por outro lado, evidenciou o caminho de volta, isto é, aspectos das condutas de estudantes e professores com interferência na composição dessas estruturas, nomeadamente as que se referem ao processo educacional desenvolvido na sala de aula, considerado neste trabalho como um sistema.

Assim, considerando as limitações da pesquisa, pois se trata de um estudo de casos múltiplos realizado numa só universidade, ficou evidenciado: 1) uma progressão de eventos que parecem se relacionar com certa inércia do sistema educacional, envolvendo relações sociais e estruturas do ambiente acadêmico; 2) esta inércia se fundamenta na mútua inculpação 
por resultados não alcançados com relação ao processo educacional; 3 ) um processo educacional oscilante entre contribuições e impactos para os quatro pilares da educação para o século XXI, o que pode estar relacionado com certo tipo de autoritarismo no dia a dia de estudantes e professores, acompanhado de novas formas de alienação (mundo fragmentado, saturado de informações); 4) este modo de ser autoritário emerge da ausência de articulação sistematizada entre aspectos cognitivos e socioemocionais, com ampla primazia da informação sobre a formação; 5) uma imposição de limites a críticas de estudantes e professores, o que parece se relacionar com uma negação parcial dos sujeitos, pessoas que, sendo humanas, desenvolvem identidades a partir de críticas cognitivas e normativas; 6) esta negação parcial dos sujeitos se fundamenta numa espécie de crítica silenciosa, caracterizada pela incompletude da manifestação de opiniões.

Alguns termos desta estrutura conceitual precisam ser esclarecidos. A inércia, compreendida como toda "falta de reação, de iniciativa, imobilismo, estagnação, apatia" (HOUAISS, 2003, p. 2088) ocorre, por exemplo, quando se mudam os tempos, mudam-se as vontades, mudam-se os políticos, mudam-se os programas, mas, depois, há efetivamente a queixa de que as coisas não mudaram no dia a dia dos envolvidos com o processo educativo - permanecem códigos e hábitos, mantendo-se as relações de poder.

$\mathrm{O}$ ato de negar alguma coisa significa, dentre outras explicações, "recusar-se a admitir, não reconhecer, não consentir, deixar de lado, deixar de revelar" (HOUAISS, 2003, p. 2599). Por sua vez, o termo sujeito quer aqui significar a síntese de uma identidade subjetiva, esta compreendida como um empenhamento em modelos culturais internalizados pelo indivíduo. Constata-se a negação do sujeito quando, por exemplo, numa relação inter ou intragrupos, os envolvidos nas relações estabelecidas têm, por determinado período, a recusa e o não reconhecimento, o abandono da capacidade de crítica cognitiva ou normativa direcionada para os processos de socialização. Nega-se, por uns e outros, a capacidade de pensar, sentir e agir. Funciona como se uma nuvem de invisibilidade encobrisse as relações sociais. Como se todos se tornassem invisíveis (WELLS, 1992).

Entende-se por autoritarismo, enquanto qualidade de quem é autoritário, "um método de fazer política no qual o governo é usado para controlar a vida de indivíduos, em vez de estar submetido a controle democrático pelos cidadãos" (JOHNSON, 1997, p. 25). Neste sentido, o sujeito autoritário é aquele "que infunde respeito, obediência [e que é] a favor do princípio da 
submissão cega à autoridade" (HOUAISS, 2003, p. 455). Segundo Bobbio, Matteucci e Pasquino (2004, p. 94), o indivíduo com personalidade autoritária trata "com arrogância e desprezo os inferiores hierárquicos e em geral todos aqueles que não têm poder e autoridade". É fenômeno humano antigo, podendo ser constatado em pequenos grupos, não sendo exclusividade de governos. Neste sentido, evidencia-se autoritarismo no processo educacional quando, por exemplo, sendo detentor de informações desconhecidas pelo estudante, o professor faz deste desconhecimento um mecanismo de controle sobre a fala daquele. Quando, a par de certas informações, prioriza o espírito competitivo e não o de aproximação pessoal com o estudante.

Espelhando esta estrutura conceitual está a pedagogia dialógica. Neste sentido, a pesquisa deixou evidentes alguns potenciais que podem contribuir para sua construção.

\subsection{Os potenciais da pedagogia dialógica}

A pesquisa identificou, nos limites de seu contorno, alguns potenciais para desenvolver maior articulação entre informar-formar, favorecendo a que se estabeleça uma pedagogia dialógica (FREIRE, 2011) como estratégia de atuação de professores, do mesmo modo alcançando todos os âmbitos da instituição. Esses potenciais, favoráveis à emancipação dos indivíduos, estão presentes no dia a dia de estudantes e professores. A ação docente e a ação institucional precisam dialogar entre si, contribuindo para transformar cada vez mais inércia em ação, autoritarismo em autoridade, negação do sujeito em sua afirmação.

Eis os potenciais, favoráveis à concretização dos quatro pilares da educação para o século XXI: 1) os participantes têm assumido uma autorresponsabilidade pela maior interação social; 2) em geral, os estudantes são críticos; 3) os estudantes valorizam atividades de pesquisa e extensão, embora não participem na medida desejada por eles; 4) as professoras estão dispostas a narrar experiências pessoais e profissionais e os estudantes se dispõem a ouvi-las; 5) os estudantes desejam ver no cotidiano escolar maior aplicabilidade de feedbacks; 6) os estudantes já têm internalizado o porquê do curso.

Desse modo, considerando os resultados da pesquisa, estabeleceu-se um paralelismo entre teoria-empiria-teoria, compondo uma estrutura em que se relacionam os conceitos "experiência social" (DUBET, 1994, 1998, 2013) e "pedagogia dialógica" (FREIRE, 2011), intercalados pelas evidências da pesquisa, conforme apresenta o Quadro 6. 
Quadro 6. Hipótese: paralelismo teoria-empiria-teoria.

\begin{tabular}{|c|c|c|}
\hline Teoria & Empiria & Teoria \\
\hline $\begin{array}{l}\text { O sistema de } \\
\text { relações sociais }\end{array}$ & \multicolumn{2}{|c|}{ Os indivíduos } \\
\hline $\begin{array}{l}\text { Características da } \\
\text { experiência social }\end{array}$ & Eixos da hipótese & $\begin{array}{l}\text { Fundamentos da } \\
\text { pedagogia dialógica }\end{array}$ \\
\hline $\begin{array}{c}\text { Condutas perpassadas } \\
\text { pela heterogeneidade } \\
\text { de princípios. }\end{array}$ & $\begin{array}{c}\text { "Atribuição de culpa ao outro". O } \\
\text { insucesso do processo educacional } \\
\text { advém da ação do Outro. } \\
\text { "O que fazer": aproveitar potenciais } \\
\text { identificados pela pesquisa, neste e } \\
\text { nos demais casos a seguir. }\end{array}$ & $\begin{array}{l}\text { "Eu-Isso", termo } \\
\text { representativo das relações } \\
\text { do indivíduo com o } \\
\text { mundo, com os sistemas de } \\
\text { relações sociais. }\end{array}$ \\
\hline $\begin{array}{l}\text { Distanciamento } \\
\text { do indivíduo com } \\
\text { relação ao sistema } \\
\text { sociocultural. }\end{array}$ & $\begin{array}{l}\text { "Crítica silenciosa". Nega-se } \\
\text { a criticidade de estudantes e } \\
\text { professores. }\end{array}$ & $\begin{array}{l}\text { "Eu", representativo do } \\
\text { ser capaz de posicionar-se } \\
\text { por intermédio da crítica, } \\
\text { cognitiva e normativa. }\end{array}$ \\
\hline $\begin{array}{l}\text { Dominação social } \\
\text { ocorre na dispersão e } \\
\text { não na unificação da } \\
\text { experiência coletiva. }\end{array}$ & $\begin{array}{l}\text { "Primazia da informação". Pouca } \\
\text { articulação entre informar-formar. }\end{array}$ & $\begin{array}{l}\text { "Eu-Tu", representativo da } \\
\text { relação interindividuais, } \\
\text { sendo de logos para logos. }\end{array}$ \\
\hline
\end{tabular}

Fonte: Elaboração dos autores (2014).

\section{Conclusão}

Desafiada a conciliar a necessidade do aumento de vagas com a efetiva inclusão social dos seus estudantes, a universidade possivelmente esteja a ser chamada para refletir e ressignificar o conceito de democratização, especialmente da perspectiva da sala de aula, um ambiente onde se desenvolvem com maior intensidade as interações sociais de alunos e professores, ricas de experiências sociais (DUBET, 1994, 1998, 2013) originárias não só da própria escola como também de outros âmbitos - a exemplo da família e do local de trabalho. Ademais, como frisado antes, trata-se de jovens, mais integrados às tecnologias da informação e comunicação e com experiências sociais bem diversas das dos seus docentes, que nasceram num mundo bastante diferente. Neste ambiente educativo, não será apenas informando, transmitindo conhecimentos, que o processo educacional contribuirá para desenvolver as diversas sequências de diálogos que se fazem necessárias para promover a efetiva inclusão social.

Tais assertivas, embora às vezes percebidas como óbvias, parecem insuficientes para evidenciar a necessidade de estabelecer uma pedagogia dialógica no âmbito de unidades educativas no contexto da universidade, capaz de sustentar, por 
exemplo, o conceito de educação para todos, não mais compreendido só como expansão da educação superior e oferecimento de oportunidades, nem a partir da ideia de instituição escolar neutra, mas, como democratização no sentido pleno do termo, que considera a diversidade sociocultural dos alunos. Dessa maneira, a democratização da universidade se converte em prova para as chamadas teorias da reprodução. Afinal, sem conseguir atender aos apelos da emancipação, a universidade pode ceder ao risco de apenas transmitir o capital econômico e cultural como originário do mérito.

Tal prova, caso seja contextualizada nos processos de desinstitucionalização, evidencia o desafio da universidade de não se deixar planificar, o que, em ocorrendo, passa a contribuir para dilatar mais ainda a fragilizada liga entre a origem social dos estudantes e os desafios do cotidiano acadêmico. Não será só transmitindo informação que o processo educacional da universidade, estando adormecido num monólogo impositivo de culturas, contribuirá para a inclusão social de seus estudantes. Ao contrário, sem se aprisionar numa espécie de teto informativo, mas assumindo uma vigorosa pedagogia dialógica (FREIRE, 2011), o processo educacional entrará numa linha "automática" de articulação entre informação e formação, incorporando tal articulação ao seu ethos, o que favorece a concretização de necessidades humanas de alunos e professores. O projeto educativo conseguirá, então, articular os diversos conteúdos presentes nesse processo, promovendo a interconexão das concepções de ser humano com os desejos de "conhecer", "fazer" e "querer-conhecer-fazer".

Estas explicações advieram da revisão de literatura sobre os assuntos implicados nesta discussão e das evidências da pesquisa empírica apresentada neste trabalho, realizada com jovens estudantes e seus professores universitários em dois cursos de uma universidade. Os resultados contribuíram para elaborar uma hipótese: em primeiro lugar, a de que uma inércia persiste em existir no sistema educacional. Ela tem na base a internalização de que o "Outro" é responsável pelo fracasso educacional. Para os professores, a universidade é o outro. Para a universidade, o professor é o outro. Para os estudantes, universidade e professores são os outros. Em segundo lugar, há uma negação do sujeito, tendo como base certos bloqueios à crítica construtiva. Em terceiro e último lugar, há comportamentos e atitudes que tendem a algum tipo de autoritarismo, viáveis com a ausência da efetiva articulação entre aspectos cognitivos e socioemocionais presentes no ato educativo.

Por onde iniciar ações favoráveis à construção de experiências sociais capazes de contribuir para o desenvolvimento humano e fortalecer a instituição universidade? Como construir pontes entre determinadas estruturas da universidade e as relações 
sociais presentes no cotidiano de estudantes e professores? Os estudos indicaram que há de se concretizar efetivamente uma pedagogia dialógica (FREIRE, 1997, 2009, 2011) na ação docente e na ação institucional para que estudantes e professores conquistem cada vez mais sua autonomia.

Coloca-se o desafio de pensar, juntamente com a busca de solução para antigos problemas da educação brasileira, como estabelecer esta pedagogia, compreendida na qualidade de algo substantivamente rico. Como se sabe, ela é revolucionária - por isto mesmo embute a ideia radical de mudança de atitude. Lembre-se que Freire (2011) caracteriza o diálogo como amor, humildade, fé, esperança e pensar crítico, o que seria capaz de edificar cada vez mais o ideal de relação horizontalizada entre os indivíduos, sedimentando confiança entre eles.

Senão, caso se cultive a pura transmissão de informações como filtro social, pouco ou nada terão valido a pena os inúmeros estudos da sociologia da reprodução. Se isto ocorrer e, como os sujeitos pesquisados são os atores mais importantes do processo educacional (professores em formação e seus professores), sem dúvida alguma, continuará mais viva do que nunca a questão fundamental desta sociologia: os sujeitos que sofrem com a reprodução reproduzirão? 


\title{
Dialogical pedagogy for higher education democratization
}

\begin{abstract}
Higher education expansion leads to enroll socio-culturally diverse students. In fact, does greater enrollment lead to increasing democratic opportunities? This research project focuses the assumed neutrality of educational institutions: do they reproduce social relations and power structures? In search of updating the dialogical pedagogy concept, it analyzed the social experiences, interaction of students and faculty members in a university. Multiple case study involved young students of two teacher education undergraduate programs. Its results show the high value attributed to friendship, creativity and mutual respect, as well as the concern with non-interested students. This project generated a hypothesis encompassing three fundamental axes of the student body and faculty social interaction: the denial of students' critical capacity by faculty, moreover the trends to inculpate each other for failure and to develop authoritarian relations.
\end{abstract}

Keywords: Higher education. Democratization. Social inclusion. Dialogical pedagogy.

\section{Pedagogía dialógica para la democratización de la Educación superior}

\section{Resumen}

La expansión de la Educación superior amplía la diversidad socio-cultural de sus estudiantes. ¿Este incremento de matriculas realmente conduce a crecientes oportunidades educativas? Esta investigación tiene foco sobre la supuesta neutralidad de las instituciones educativas: ¿ellas reproducen de facto las relaciones sociales, así como las estructuras de poder? En búsqueda de la actualización del concepto de pedagogía dialógica, esta investigación analizó las experiencias sociales de interacción entre estudiantes y profesores de una universidad. Se efectuó un estudio de casos múltiples con docentes y estudiantes de dos programas de formación de maestros. Los resultados señalaron el alto valor atribuido a la amistad, creatividad y respeto mutuo, así como la preocupación con el desinterés de parte de los estudiantes. Entonces, se generó una hipótesis, involucrando tres ejes fundamentales de la interacción entre los dos grupos: la negación de la capacidad crítica de los estudiantes por sus profesores, además de las tendencias a culparse mutuamente por el fracaso y a desarrollar relaciones autoritarias.

Palabras clave: Educación Superior. Democratización. Inclusión social. Pedagogía dialógica. 


\section{Referências}

ALARCÃO, I. Professores reflexivos em uma escola reflexiva. 6. ed. São Paulo: Cortez, 2008.

BARDIN, L. Análise de conteúdo. 5. ed. Lisboa: Edições 70, 2009.

BAUMAN, Z. Modernidade líquida. Rio de Janeiro: Jorge Zahar, 2001.

BOBBIO, N.; MATTEUCCI, N.; PASQUINO, G. Dicionário de política. 12. ed. Brasília: Editora Universidade de Brasília, 2004.

BOLÍVAR, A. A educação em valores: o que aprendemos com o seu esboço e o seu desenvolvimento curricular em Espanha? In: TRILLO, F. (Coord.). Atitudes e valores no ensino. Lisboa: Instituto Piaget, 2000. p. 123-70.

BOURDIEU, P.; PASSERON, J. C. Les héritiers: les étudiants et la culture. Paris: Éd. de Minuit, 1964.

BRASIL. Instituto Nacional de Estudos e Pesquisas Educacionais Anísio TeixeiraINEP. Censo da educação superior 2012: resumo técnico. Brasília, DF: INEP, 2014. . Ministério da Educação e do Desporto. Secretaria da Educação Fundamental. Parâmetros curriculares nacionais: introdução aos parâmetros curriculares nacionais. Brasília, DF, 1997.

. Ministério da Educação. Conselho Nacional de Educação. Parecer CNE/CSE $n^{\circ} 492$, de 3 de abril de 2001. Diretrizes Curriculares Nacionais dos cursos de Filosofia, História, Geografia, Serviço Social, Comunicação Social, Ciências Sociais, Letras, Biblioteconomia, Arquivologia e Museologia. Brasília, DF: Conselho Nacional de Educação, 2001.

. Ministério da Educação. Conselho Nacional de Educação.

Resolução CNE/CP $n^{\circ} 1$, de 15 de maio de 2006. Institui Diretrizes

Curriculares Nacionais para o Curso de Graduação em Pedagogia, licenciatura. Brasília, DF: Conselho Nacional de Educação, 2006.

BUARQUE, C. A aventura da universidade. São Paulo: Editora da Universidade Estadual Paulista; Rio de Janeiro: Paz e Terra, 1994.

BUBER, M. Eu e tu. 10. ed. São Paulo: Centauro, 2009.

CASASSUS, J. Fundamentos da educação emocional. Brasília, DF: Unesco, Liber Livro Editora, 2009. 
COLL, C. Psicologia e currículo: uma aproximação psicopedagógica à elaboração do currículo escolar. São Paulo: Ática, 2001. (Fundamentos, 123).

COLL, C. et al. Os conteúdos na reforma: ensino e aprendizagem de conceitos, procedimentos e atitude. Porto Alegre: Artes Médicas, 1998.

DELORS, J. et al. Educação um tesouro a descobrir: relatório para a UNESCO da Comissão Internacional sobre Educação para o Século XXI. São Paulo: Cortez; Unesco no Brasil, 1998.

DEMO, P. Educar pela pesquisa. 8. ed. Campinas: Autores Associados, 2007.

DICK, H. Gritos silenciados, mas evidentes: jovens construindo juventude na História. São Paulo: Loyola, 2003.

DUBET, F. A escola e a exclusão. Cadernos de Pesquisa, São Paulo, n. 119, p. 29-45, 2003. doi:10.1590/S0100-15742003000200002

. A formação dos indivíduos: a desinstitucionalização.

Contemporaneidade e Educação, Rio de Janeiro, v. 3, p. 27-33, 1998.

. Democratização escolar e justiça da escola. Educação, Santa Maria, v. 33, n. 3, p. 381-93, 2008. doi:10.5902/19846444

. El declive de la institución. Barcelona: Gedisa, 2013.

. Sociologia da experiência. Lisboa: Instituto Piaget, 1994.

FREIRE, P. Pedagogia da autonomia: saberes necessários à prática educativa. São Paulo: Paz e Terra, 2009.

. Pedagogia da esperança: um reencontro com a pedagogia do oprimido. São Paulo: Paz e Terra, 1997. . Pedagogia do oprimido. 50. ed. São Paulo: Paz e Terra, 2011.

GIL, A. C. Como elaborar projetos de pesquisa. 4. ed. São Paulo: Atlas, 2002. GOFFMAN, E. A representação do eu na vida cotidiana. Petrópolis: Vozes, 1985.

GOMES, C. A. (Org.). Juventudes: possibilidades e limites. Brasília, DF: Unesco: UCB, 2011.

GOMES, C. A.; VASCONCELOS, I. O.; LIMA, D. A. Juventude: se correr o bicho pega. Revista Diálogos, Brasília, v. 17, n. 1, p. 51-62, 2012. 
HOUAISS, A. Dicionário Houaiss da língua portuguesa. Lisboa: Círculo de Leitores, 2003.

INCLUIR. In: INSTITUTO ANTÔNIO HOUAISS. Dicionário eletrônico Houaiss da língua portuguesa. Rio de Janeiro: Objetiva, 2007.

JOHNSON, A. G. Dicionário de sociologia: guia prático da linguagem sociológica. Rio de Janeiro: Jorge Zahar, 1997.

JOSPIN, L. Discurso na abertura da Conferência Mundial sobre o Ensino Superior. In: FÓRUM CRU, 5., Tendências da educação superior para o século XXI. Brasília, DF: Unesco, 1999. p. 47-50.

MANCEBO, D.; VALE, A. A.; MARTINS, T. B. Políticas de expansão da educação superior no Brasil, 1995-2010. Revista Brasileira de Educação, Rio de Janeiro, v. 20, n. 60, p. 31-50, 2015. doi:10.1590/S1413-24782015206003

MASETTO, M. T. Didática: a aula como centro. 4. ed. São Paulo: FTD, 1997.

MAUGER, G. La teoría de la reproducción frente al reto de la democratización escolar. In: Carvacho, C. B. et al. La escolarización de los adolescentes: desafíos culturales, pedagógicos y de política educativa. Buenos Aires: IIPE-UNESCO, 2012. p. 19-53.

MEHTA, S. Pequenas e grandes estórias: para além de teorias em disputa, rumo ao "multiálogo". In: COWEN, R.; KAZAMIAS, A. M.; ULTERHALTER, E. Educação comparada: panorama internacional e perspectivas. Brasília: Unesco/Capes, 2012. p. 647-69.

MORAIS, M. C. Ecologia dos saberes: complexidade, transdisciplinaridade e educação: novos fundamentos para iluminar novas práticas educacionais. São Paulo: Antakarana/WHH-Willis Harman House, 2008.

MORIN, E. A cabeça bem-feita: repensar a reforma, reformar o pensamento. 15. ed. Rio de Janeiro: Bertrand Brasil, 2008.

ORGANISATION FOR ECONOMIC CO-OPERATION AND DEVELOPMENT - OECD. Education at a glance 2010. Paris: OECD, 2010.

PAIS, J. M. Ganchos, tachos e biscates: jovens, trabalho e futuro juvenis. 2. ed. Porto: Ambar, 2003. 
RISTOFF, D. Perfil socioeconômico do estudante de graduação: uma análise de dois ciclos completos do ENADE (2004 a 2009). Cadernos do GEA, Rio de Janeiro, n. 4, jul./dez. 2013.

ROGGERO, R. Contradições na educação superior: o perfil do jovem contemporâneo e o discurso pedagógico. Acta Semiótica e Linguística, v. 11, p. 167-85, 2006.

ROTTER, J. B. Internal versus external control of reinforcement: a case history of a variable. American Psychologist, Washington, D.C., v. 45, n. 4, p. 489-93, 1990.

SALMON, W. C. Lógica. 3. ed. Rio de Janeiro: Prentice-Hall do Brasil Ltda., 1993.

SANTOS, B. S. Pela mão de Alice: o social e o político na pós-modernidade. 10. ed. São Paulo: Cortez, 2005. . Renovar a teoria crítica e reinventar a emancipação social. São Paulo: Boitempo, 2007.

SARTRE, J.-P. El hombre y las cosas. Buenos Aires: Losada, 1960.

SAVAGE, J. A criação da juventude: como o conceito de teenage revolucionou o século XX. Rio de Janeiro: Rocco, 2009.

SÍVERES, L. A extensão como um processo aprendente. In: FREITAS, L. G.; CUNHA FILHO, J. L.; MARIZ, R. S. (Org.). Educação superior: princípios, finalidades e formação continuada de professores. Brasília, DF: Universa: Líber Livro, 2010. p. 101-20.

SPOSITO, M. P. (Org.). O estado da arte sobre juventude na pós-graduação brasileira: educação, ciências sociais e serviço social (1999-2006). Belo Horizonte: Argvmentvm, 2009.

STAKE, R. E. A arte da investigação com estudos de caso. Lisboa: Fundação Calouste Gulbenkian, 1995.

TAVARES, J. Uma sociedade que aprende e se desenvolve: relações interpessoais. Porto: Ed. Porto, 1996.

THOMPSON, J.B. A mídia e a modernidade: uma teoria social da mídia. Petrópolis: Vozes, 1998.

TOURAINE, A. Iguais e diferentes: poderemos viver juntos? Lisboa: Instituto Piaget, 1997. 
UNITED NATIONS CHILDREN'S FUND - Unicef. An overview of child well-being in rich countries. Florence, 2007. (Innocenti Report Card, v. 7).

UNITED NATIONS EDUCATIONAL, SCIENTIFIC AND CULTURAL ORGANIZATION - Unesco. Tendências da educação superior para o século XXI. Brasília, DF: Unesco/CRUB, 1999.

\section{CONFERENCIA MUNDIAL SOBRE LA EDUCACIÓN}

SUPERIOR - 2009: la nueva dinámica de la educación superior y la investigación para el cambio social y el desarrollo. Paris: Unesco, 2009.

VASCONCELOS, I. C. O. Conteúdos atitudinais como o lugar da investigação no processo educacional. Educação, Gestão e Sociedade, Jandira, v. 2, n. 6, p. 1-14, jun. 2012.

VIEIRA, E. Sociologia da educação: reproduzir e transformar. 3. ed. São Paulo: FTD, 1996.

WELLS, H. G. O homem invisível. Sintra: Europa-América, 1992.

WILBER, K. A união da alma e dos sentidos: integrando ciência e religião. São Paulo: Cultrix, 2006.

YIN, R. K. Estudo de caso: planejamento e métodos. 4. ed. Porto Alegre: Bookman, 2010.

\section{Informações dos autores}

Ivar César de Oliveira de Vasconcelos: Doutorado em Educação pela Universidade Católica de Brasília - UCB. Professor titular da Universidade Paulista - UNIP. Contato: ivcov@hotmail.com

Candido Alberto Gomes: Doutorado em Educação, Universidade da Califórnia, Los Angeles, Estados Unidos. Professor titular da Universidade Católica de Brasília - UCB. Contato: clgomes@terra.com.br

Este trabalho foi parcialmente possível graças ao apoio da Coordenação de Aperfeiçoamento de Pessoal de Nível Superior (CAPES), relativamente a uma bolsa de estudos concedida ao primeiro autor para realizar estágio de doutoramento na Universidade de Lisboa (processo n. ${ }^{\circ}$ 99999.011691/2013-01). 